\title{
BMJ Open Providing care to refugees through mainstream general practice in the southern health region of New Zealand: a qualitative study of primary healthcare professionals' perspectives
}

\author{
Lauralie Richard (1) , Georgia Richardson, Chrystal Jaye, Tim Stokes (b)
}

To cite: Richard L,

Richardson G, Jaye C, et al. Providing care to refugees through mainstream general practice in the southern health region of New Zealand: a qualitative study of primary healthcare professionals' perspectives. BMJ Open 2019;9:e034323. doi:10.1136/ bmjopen-2019-034323

- Prepublication history and additional material for this paper are available online. To view these files, please visit the journal online (http://dx.doi. org/10.1136/bmjopen-2019034323).

Received 14 September 2019 Revised 25 November 2019 Accepted 10 December 2019

Check for updates

(c) Author(s) (or their employer(s)) 2019. Re-use permitted under CC BY-NC. No commercial re-use. See rights and permissions. Published by BMJ.

General Practice \& Rural Health, Dunedin School of Medicine, University of Otago, Dunedin, New Zealand

Correspondence to

Dr Lauralie Richard;

lauralie.richard@otago.ac.nz

\section{ABSTRACT}

Objective To explore the perspectives of primary healthcare (PHC) professionals providing care to refugees through mainstream general practice.

Design Qualitative exploratory design with semistructured interviews subjected to inductive thematic analysis.

Setting and participants Nine general practices enrolled in the Dunedin Refugee Resettlement Programme, in New Zealand (NZ)'s southern health region. Participants included nine general practitioners and six practice nurses. Results Three analytical constructs were identified: relational engagement with refugees, refugee healthcare delivery and providers' professional role shaped by complexity. Building meaningful relational connections involved acknowledging refugees' journeys by getting to know them as people. This was instrumental for the development of an empathetic understanding of the complex human trajectories that characterise refugees' journeys to NZ. Participants encountered challenges in providing care to refugees with respect to time-limited consultations, variable use of interpreter services, fragmentation of care between agencies and need for improved health infrastructure to ensure a fluid interface between PHC, secondary care and community support services. The current business model of $\mathrm{NZ}$ general practice was perceived to interfere with value-driven care and discouraged tailoring of care to specific patient groups, raising concerns about the 'fit' of mainstream general practice to address the complex healthcare needs of refugees. Meeting the needs of refugees across the social determinants of health involved a lot of 'behind the scenes work' particularly in the absence of shared information systems and the lack of well-established referral pathways to connect refugees to services beyond the health sector. This led to providers feeling overwhelmed and uncertain about their ability to provide appropriate care to refugees.

Conclusions This study provides rich context-specific findings that enhance PHC responsiveness to the needs of refugees in NZ.

\section{INTRODUCTION}

Refugee health has become an issue of global importance, with significant implications for
Strengths and limitations of this study

- This is the first in-depth qualitative study seeking the perspectives of general practitioners and practice nurses caring for recently arrived refugees through mainstream general practice in New Zealand.

- Detailed reflections were shared by primary healthcare professionals on the relational and structural dynamics enabling and restricting service delivery to refugees, highlighting implications at health system, policy and practice levels.

- All participants were actively involved in providing care to refugees which contributed to the richness of the data, and some critically reflected on their own experiences of migration to New Zealand.

- The study focused on general practices from a single health region which provided rich context-specific findings to the benefit of the local health system.

- The study has been conducted with a relatively small sample of primary healthcare providers; more research is needed to further nuance and contextualise the findings.

health systems, policy and practice. ${ }^{1}$ Refugees are generally considered 'vulnerable', with mental, physical and social health needs likely to be high and complex. They have often experienced severe trauma, coming from countries in situations of long-term war or conflict. $^{2}$ These traumatic experiences are associated with cumulative vulnerability, including disrupted access to healthcare, social deprivation and poor living conditions, leading to important disparities in health. ${ }^{3}$ Refugees are also more likely to have increased morbidity, poor health outcomes and a reduced life expectancy. ${ }^{45}$ On resettlement, refugees face considerable barriers in accessing and using health services, often due to language and communication challenges, financial hardships, difficulties in navigating 
health systems, transportation problems and acculturation challenges. ${ }^{36-10}$

The large-scale movement of refugees has left international health systems facing growing pressure to respond effectively to the needs of refugees. ${ }^{11}$ Health systems may not be structurally configured to provide culturally responsive care, and these challenges can impact on healthcare professionals' ability to deliver high-quality care to refugees. ${ }^{12}$ Health services for refugees often experience gaps in delivery and access, poor coordination and service fragmentation. ${ }^{12-14}$ Primary healthcare (PHC) teams are at the frontline of healthcare provision for refugees-assessing priority health needs, managing care and facilitating referrals to appropriate services. ${ }^{14} 15$ A recent qualitative synthesis of the challenges and facilitators for PHC professionals providing care to refugees found these related to the healthcare encounter (eg, communication, cultural understanding), the local healthcare system (eg, connecting with other services, resourcing) and the resettlement process. ${ }^{16}$

New Zealand (NZ) research into refugee healthcare delivery is limited. Previous research has focused on refugee health status ${ }^{17-23}$ and specific aspects of healthcare delivery such as the use of interpreting services ${ }^{24}$ and access and use of medicines, ${ }^{25}$ with evidence specific to PHC remaining very limited. ${ }^{26}{ }^{27}$ We therefore aimed to explore the perspectives of PHC professionals providing care to refugees through mainstream general practice in one region of $\mathrm{NZ}$ in order to provide rich context-specific accounts and identify opportunities for practice improvement, and to foster transformative change of local health systems.

\section{METHODS}

\section{Research setting}

Refugees arrive in NZ through three pathways: the NZ Refugee Quota Programme (under the Office of the United Nations High Commissioner for Refugees regular resettlement programme), as family members of refugees (family reunification scheme) and as asylum seekers. ${ }^{28}$ All refugees entering NZ through the Quota programme are given permanent resident status and thus are eligible for several benefits and supplementary allowances, including for example unemployment-related benefits, access to legal aid and housing assistance. ${ }^{29}$ Quota refugees have access to free healthcare at publicly funded health services.

Provision of PHC in NZ occurs through a strong first contact general practice system. General practitioners (GPs) in NZ are mostly independent, self-employed healthcare professionals funded at $50 \%$ by a capitated government-determined subsidy paid through Primary Health Organisations (PHOs). ${ }^{30}$ The remainder of general practice funding comes from individual patient co-payments, which are set by each general practice.

The Dunedin Refugee Resettlement Programme commenced in 2016 with an annual target/quota of approximately 180 refugees originating mainly from Syria. On resettlement in Dunedin, a city in the lower South Island of NZ (population 120000), ${ }^{31}$ the local PHO allocates refugees to a general practice. Uptake of refugees by general practices is entirely voluntary. Only general practices enrolled in the programme provide care to quota refugees on resettlement. At the time of the study, 18 general practices were enrolled in the programme. General practices are provided with payment vouchers to cover for consultation costs with refugee patients. Consultations usually last 1 hour for any new refugee patient's first appointment, and $30 \mathrm{~min}$ for all subsequent appointments. Financial assistance to general practices is provided for the first 2 years of each refugee patient's resettlement, after which they have to cover individual patient co-payment charges to access PHC services.

\section{Design and sampling}

The study used a qualitative exploratory design. ${ }^{32} \mathrm{~A}$ purposive sampling approach was used to recruit GPs and practice nurses (PNs) from general practices enrolled in the Dunedin Refugee Resettlement Programme. A maximum variation strategy ensured breadth in terms of the profiles of general practices (eg, practice size, structure), locations (eg, areas of high vs low diversity, variable level of deprivation) and providers involved (eg, ethnicity, gender, qualifications, number of years of experience).

\section{Data collection}

Semistructured interviews were conducted by GR with GPs and PNs between May and September 2018. The interviews used a topic guide (online supplementary file 1) designed to elicit participant's accounts of providing care to refugees in their own words. The topic guide was refined throughout the interviewing process to further investigate emerging themes. The interviews lasted 1 hour on average and were conducted at the participant's preferred location. Interviews were digitally recorded, transcribed verbatim and validated by participants.

\section{Data analysis}

We used a multistage inductive thematic approach for qualitative data analysis, ${ }^{33}$ assisted by use of Atlas.ti software. All transcripts were independently read and coded by an experienced dyad of coders (LR, GR). Data immersion occurred through repeated readings of the transcripts. An initial list of codes was generated iteratively through a first round of coding and discussed (LR, GR), with new codes being created as necessary. Codes were assigned to key sections of data to reflect the content. The few discrepancies identified were resolved through discussions and agreed by consensus. A subset of transcripts were also reviewed with other members of the research team (TS, CJ). This led to the development of a preliminary coding framework generated by regrouping codes with common features into emergent themes. The coding framework was discussed with the research team (LR, GR, TS, CJ) and further refined and validated 


\begin{tabular}{|c|c|}
\hline Participant demographics & Participants, $n$ \\
\hline Health professional & 15 \\
\hline General practitioner (GP) & 9 \\
\hline Practice nurse (PN) & 6 \\
\hline \multicolumn{2}{|l|}{ Gender } \\
\hline Female & 12 \\
\hline Male & 3 \\
\hline \multicolumn{2}{|l|}{ Ethnicity* } \\
\hline New Zealand European & 13 \\
\hline Othert & 7 \\
\hline \multicolumn{2}{|l|}{ Total years of experience in clinical practice } \\
\hline $0-5$ years & 2 \\
\hline $6-10$ years & 2 \\
\hline $11-20$ years & 5 \\
\hline $20+$ years & 6 \\
\hline $\begin{array}{l}\text { Health professionals who had completed } \\
\text { training relating to refugee health }\end{array}$ & 10 \\
\hline General practitioner & 7 \\
\hline Practice nurse & 3 \\
\hline General practice demographics & Practices, $\mathbf{n}$ \\
\hline Practice size & 9 \\
\hline $1-4$ GPs & 3 \\
\hline 5-9 GPs & 3 \\
\hline $10+$ GPs & 3 \\
\hline
\end{tabular}

*Ethnicity is total response.

†Non-New Zealand European categories were conflated to ensure participant anonymity.

through a second round of coding (LR, GR). Emerging themes were finally assigned to three overarching analytical constructs. A reflexive diary of the analysis was maintained. This provided an audit trail of the development of the framework and also promoted reflexive research practice. The COnsolidated criteria for REporting Qualitative research ${ }^{34}$ were used to inform reporting of the findings (online supplementary file 2).

\section{Patient and public involvement}

We have not involved patients or members of the general public in the design or conduct of this study.

\section{RESULTS}

We interviewed nine GPs and six PNs: all were involved in providing care to refugees. The characteristics of participants are shown in table 1 .

The thematic findings describing PHC practice with refugees are reflected across three analytical constructs: relational engagement with refugees, refugee healthcare delivery and providers' professional role shaped by complexity. Illustrative quotes from participants are provided.

\section{Relational engagement with refugees}

Building meaningful relational connections with refugees was identified as the core foundation to PHC practice.

\section{Acknowledging people's journeys}

Acknowledging refugees' journeys by 'getting to know them as people' and listening to their stories of dislocation as well as stories of hope and resilience was found to be critical to build relationships respectful of their unique life trajectories. Participants shared an empathetic understanding of refugees' stories and reflected back on how their complex human trajectories resonated with them, exposing their own vulnerability as healthcare professionals. Participants reflected on the importance of acknowledging what refugees have been through to develop a more nuanced understanding of their complex migration journeys to NZ:

[R] espect them as people ... respect what they have been and what they can be ... They were lawyers, policemen, doctors, teachers, and they come here and all of a sudden they have nothing... That's something to just always keep in mind. (PN126)

Acknowledging what refugees have been through also meant respecting differences in expectations to avoid unmet needs and allow for trustful relationships to develop. This included managing refugees' expectations regarding health delivery within a system that operates very differently to what they are used to, but also managing their own expectations as healthcare professionals, with refugee patients presenting to the practice with priority needs that often differed from their own. Establishing dialogue around those contrasting perspectives and providing emotional support to reduce feelings of uncertainty were important to facilitate meaningful engagement.

\section{Cultural sensitivity and openness to difference}

Relational closeness was developed through an openness to difference. Participants referred to the importance of demonstrating a genuine interest in refugees' cultural practices, norms and values. Setting aside professional assumptions about 'what is best to do' and avoiding 'treating everybody the same' reflected cultural sensitivity and provided foundation to culturally appropriate care:

[I] t's no good saying: " I'll just treat them like anybody else"... That's not what equity and justice are all about. You've actually got to recognise that refugees need to be treated differently because otherwise you will not meet their needs, and that's part of cultural competency. (GP827)

Cross-cultural interactions, however, could be challenging at times and participants acknowledged the importance of cultural competency training to build 
confidence and skills for the relational encounter through cultural diversity. Participants also discussed the importance of understanding the nuances of cultural differences and their potential impact on the health of refugee patients, including impact on health service utilisation. Uptake of cultural competency training, however, remained variable, with a third of our participants not having completed any training relating to refugee health. Furthermore, only very few people at the practice were generally allocated time to attend training sessions due to busy practice schedules.

\section{Translating experiential knowledge into practice}

Participants' journeys shaped the ways in which they related to cultural diversity in their professional practice. Participants with experience of working in culturally diverse contexts felt that they had a somewhat advantageous perspective on negotiating cultural issues. In particular, participants gave detailed reflections on their own experiences of travelling and working overseas for professional or humanitarian work including with refugees and having to adapt to cultural diversity. Experiential knowledge acquired through exposure to different cultures allowed them to develop an understanding of 'difference' in terms of norms of culture and gender which they would then translate into their practice with refugees in NZ. Participants from migrant backgrounds shared their own experiences of relocation, and although contrasting to those of refugees, this helped them with building a connection between what they had been through and the way that they can support their refugee patients resettling locally:

I've worked all over the world including with refugees ... [I]'ve lived in different cultures myself and I had to adapt. [A]ll the things I have experienced and learned are actually things I can use to help somebody else. (GP200)

\section{Making a difference}

Providing care to refugees was generally perceived as an opportunity to contribute to a 'bigger cause', in reference to the humanitarian values underpinning refugee healthcare. Participants' willingness to help was reflected by an overarching sense of moral commitment and responsibility. Through caring for refugees, participants felt that the work they were doing was worthwhile and that impacting on the lives of their refugee patients, even the slightest, was extremely gratifying:

[I]t's been a fulfilling experience ... doing something worthwhile $\ldots$ and that sort of warm fuzziness ... [the] constant remembering of what these people have been through, and if you can make a difference, then that's really worthwhile. (GP404)

Providing care to refugees was seen as a transformative experience, with some participants taking on advocacy and volunteering roles in their community to promote a culture of acceptance that celebrated diversity. Overall, participants' relational experiences reflected a caring approach aimed at nurturing people's potential, providing opportunities for them to pursue fulfilling lives in $\mathrm{NZ}$ and creating a relational space at the practice that is culturally safe for everyone.

\section{Refugee healthcare delivery}

Key components of refugee healthcare delivery were identified and reflected either challenges that our participants had faced or strategies used to enhance service responsiveness.

\section{Time commitment}

Providing care to refugees through mainstream general practice challenges the time-restricted consultation structure. Participants mentioned needing to dedicate more time to consultations with refugee patients than with most other patients. The time allocated to each consultation was still perceived to be too limited despite financial assistance provided to general practices through the voucher system to cover for $30 \mathrm{~min}$ appointments. Participants often mentioned having to compensate for this at the detriment of the experience of care provided to other patients, extended waiting times and sometimes considerable disruption to their work schedule. The longer time required for consultations was sometimes perceived as a burden on the system:

[Consultations] just are long and that is never going to shift ... Theoretically $30 \mathrm{~min}$, but generally much longer, disrupted, and throw the rest of your day out. (GP794)

\section{Use of interpreter services}

The use of interpreter services (interpreters physically present in the consultation) was generally perceived as an enabler to providing high-quality care to refugees. Beyond language translation, interpreters were also considered to be 'cultural brokers'-helping with understanding the cultural meanings of certain words, cultural behaviours and gender roles during consultations. General practices are free to use interpreter services at no cost and this was seen as an important incentive to interpreter bookings in order to facilitate communication with refugee patients. However, despite the availability of interpreter services at no cost and the positive experiences of interpreted consultations by participants, important variations in the uptake of these services were noted including the use of a 'make do' approach with the use of other means such as Google Translate or relying on family members for translation in the consultation room, including children. Those challenges most often occurred when refugee patients would present to the practice without an appointment and needed to be seen urgently, when interpreters had not been previously booked on the basis that a family member speaks English well enough to substitute interpreter assistance, or when an interpreter had been 
booked but the patient's visit extended beyond the scheduled timeframe, leaving the remainder of the consultation without an interpreter.

\section{Interface with other services}

Participants highlighted the importance of connecting with other services and facilitating referrals to appropriate resources to facilitate management of refugee care and ensure timely access to services for refugees. Navigation roles (eg, cross-cultural health navigators from the local PHO and Red Cross volunteers) were instrumental in enabling connections between general practices and the other providers in the network and helping refugees navigate the health system. Despite the perceived benefits of navigation support, those roles often relied on very few individuals covering for an entire resettlement region, with concerns expressed about sustainability of navigation assistance in the long run. Participants also reported uncertainty about the role of the different refugee services providers in the network which would sometimes lead to apprehension towards referrals to other services. Participants were more familiar with referring patients to health resources and many struggled with endeavouring to refer refugee patients to the wider range of social and community support services required to meet their needs, including employment and housing. Some participants described a 'disconnect' between services and expressed feelings of professional isolation (silo work) in terms of coordinating care across the primary and secondary care interface and beyond the health sector:

[W] e're just one cog in the whole system. Everybody needs to talk to each other more ... to have everyone on the same page so that [refugees'] needs are being met, and that there's no duplication. ... We need more communication, there's a bit of a disconnect. (GP878)

Misunderstandings about refugees' entitlement to care were also common occurrence, particularly in the early stages of the resettlement programme. The need to clarify refugees' rights in accessing healthcare led GPs to write justification letters to various services to ensure timely access to healthcare, particularly to secondary care.

\section{Adapting delivery arrangements}

Different ways of adapting healthcare delivery to refugee patients were reported by participants. These initiatives were implemented on a voluntary basis with the intention of making services more efficient and also more responsive to the needs of refugees. Examples of initiatives included the allocation of gender-concordant providers at consultations, the implementation of group appointments for all women or men of a same family, or the establishment of a welcome session outside normal business hours for new refugee cohorts to introduce them to staff at the practice, provide information about the role of general practice, explain how to book appointments and address any other informational needs of refugees, including how to navigate the wider health system. Overall, these initiatives were perceived to be fostering culturally appropriate practice, facilitating relationship building and trust, as well as helping with providing smoother pathways to and through general practice for refugee patients. Despite perceived benefits of adopting flexible delivery arrangements, no formal support was provided to general practices to implement such initiatives.

\section{Appropriate health infrastructure}

Participants shared reflections about the ways in which they perceived the implementation of the refugee resettlement programme locally and implications for the provision of PHC through mainstream general practice. Overall, the implementation process was reported to be 'reactionary', with participants highlighting a perceived lack of preparedness of the systems in place. A resourcedemand imbalance was pervasive in the discourse of participants, and this was particularly reflected in views about the planning of resources such as the duration of support provided to general practices to allow refugees to access care at no cost (eg, 6-month initial coverage increased to 2 years to meet actual demands) and the financial compensation to cover for extended consultations (which was still perceived to be insufficient):

[I] nitially the intention was for 6 months of funding to support consultations, over time, it became quite clear that 6 months was absolutely inadequate ... I hadn't appreciated quite how much, basically, we made it up as we went along. Like, "Oh, okay. We didn't foresee that we were going to need interpreted consultations for so long and lots more interpreters." (GP949)

[Things are being managed] in a reactionary way ...

[T] here's just not enough resources... (GP632)

The lack of infrastructure to facilitate inter-service and inter-sectoral coordination of services (eg, shared information systems) was identified as an important barrier to promoting continuity of care. Participants particularly mentioned the lack of processes in place for ensuring coordination of health information about refugee patients from their initial health assessments at Mangere Refugee Resettlement Centre (the national reception programme), and having to chase up health information which would sometimes generate delays in providing timely access to care, including immunisation. It was also felt that the lack of well-established referral pathways to the wider range of refugee support services, and the lack of human resources to provide navigation support to refugees, were impeding on providers' ability to ensure timely access to care. Participants working in smaller practices reported challenges relating to the lack of physical spaces to accommodate for large families, interpreters and volunteers in small consultation rooms and reception areas which were associated with disruption of practice functioning. They also talked about the importance of discussing complex cases and debriefing with colleagues 
to discuss challenging situations they had faced in practice with refugee patients. However, most participants had to rely on informal peer support networks. The lack of multidisciplinary support for GPs and PNs at general practices and the absence of best practice guidelines to PHC for refugees were perceived to be impacting on providers' confidence in their ability to manage refugee care.

\section{Mainstream general practice model: fit for purpose?}

The parameters of the current business model of NZ general practice were seen as compromising the system's responsivity to refugees. The financial imperatives underpinning the business model of general practice, including relatively short consultation times, were perceived to be interfering with value-driven care and tailoring of care to specific groups of patients, raising concerns about the 'fit' of mainstream general practice to address the complex healthcare needs of refugees. The business model of general practice was perceived to be in competing demand with moral responsibility in the eyes of many participants.

It's a private business. It's finding that balance between social responsibility versus financial viability. (GP949)

I'm not sure if [general practice] is where [refugee care] is most appropriately held, because it's a fastpaced short-appointment-time service that's quite busy ... it's a lot of work, and it's not fitting in appropriately with the rest of what we do here. (GP202)

\section{Professional role shaped by complexity}

The last theme depicts the professional role of PHC participants in the context of refugee healthcare.

\section{Addressing healthcare needs across the social determinants of health}

Refugees were generally portrayed as 'high needs' patients, with priority needs ranging from physical, mental, oral health needs, to a wider range of social needs including support for navigating the health system, language assistance, legal aid, help with finding sustainable employment and healthy housing:

Refugees are a relatively high-needs population because of their previous experiences, so they will have both physical and mental health needs ... then of course employment is difficult. They've got language barriers ... the qualifications they have are not necessarily recognised. They've got social needs and financial constraints as well. ... they need help with navigating the system ... so we will sometimes go beyond our (typical) role so they can get the help they need. (PN184)

The problems presented by refugee patients were seen to require approaches which go beyond standard clinical practice for both GPs and PNs. In order to address refugees' needs, participants talked about employing a 'social approach' that considers the wider social determinants of health. This involved connecting with various services beyond the health sector and advocating for patients' rights to access services. Considerable time needed to be invested in strengthening existing community networks and creating new networks and pathways to facilitate navigation to and through services:

[The role] is wider than just your standard general practice role because refugees have a lot of other needs outside of health... it is like being a "communal garden GP"... the role is community focused and more social. (GP949)

\section{Invisibility of the role and perceived lack of value}

Providing care to refugees involved a lot of 'behind the scenes work', particularly for retrieving previous health information in the absence of shared information systems, building new referral pathways and connecting refugees to services beyond the health sector. This 'background work' would range from more simple tasks of filling out extra paperwork to more complex tasks of developing relationships with other service providers and adapting delivery arrangements to ensure refugee patients are being seen according to their needs. Participants would refer to this as 'charity work' and 'unpaid' work, with considerable additional burden on reception staff, limited numbers of nursing resources and GPs' caseloads already at full capacity:

We do a lot of extra work with [refugees] in the consultations, and then there's quite a lot of behind the scenes work that we do as well ... it's like volunteer work, we were aware that we weren't going to get paid for it. (G404)

There was a perceived lack of value for all the efforts that needed to be invested in creating the conditions for ensuring that refugees' healthcare needs are being met. Invisibility of the role is portrayed by the following quote:

[T] here's a sense of you're just out there doing things and no one can see you and no one really [cares] ... there is not good understanding of the amount of work that's happening with [refugees] ... I don't think [our role] is valued properly. (GP794)

\section{Disempowerment in response to lack of support}

The perceived lack of support and recognition of the role expressed by participants, coupled with the complex reality of refugee healthcare in a system already subjected to significant stress and limited resources, can lead to professional distress. Participants reported feeling quite overwhelmed at times and uncertain about their ability to meet the challenges that providing care to refugees entail. This quote from a GP participant reflects how challenging this can be:

I've found it more difficult than I expected. I've found the health stuff pretty overwhelming. ... Feels like 
more than I can manage ... people come to me with these huge lists of diagnoses, referrals everywhere, issues that need to be followed up and no systems in place ... I've felt like I've drowned in that really ... I've found it unwieldy, hard to manage... the practice has really struggled. (GP794)

The inability to help as they would hope to was frustrating and left participants feeling helpless at times:

$[\mathrm{M}] \mathrm{y}$ heart would just sink when I saw them on my list ... [I] t's really frustrating ... and that frustration comes with not being able to really help them like I'd want to. (PN656)

Commitment to make things work in the face of challenges was driven by a strong sense of moral responsibility, but the ability to sustain these efforts in the long run due to a lack of resources was questioned by many participants:

There's a sort of a practice commitment to do this even if it was going to be a struggle ... [we were] well aware that [the support] we were offered was not going to be enough time or resources ... and the rest of it would have to come from us. ... I just wonder how that will go in perpetuity (GP404)

Many participants also reported dissatisfaction with the disparities between general practices in terms of uptake of refugee patients, and the disengagement of some general practices early on after the implementation of the resettlement programme. This situation was perceived to be adding increased pressure on a selected number of practices already under stress, with participants expressing concerns for the sustainability of PHC delivery to refugees in the longer term.

\section{DISCUSSION}

\section{Statement of principal findings}

Findings from this study point to the pivotal role of PHC teams in managing refugee healthcare. Three analytical constructs were identified: relational engagement with refugees, refugee healthcare delivery and providers' professional role shaped by complexity. Building meaningful relational connections involved acknowledging refugees' journeys by getting to know them as people. This was instrumental for the development of an empathetic understanding of the complex human trajectories that characterise refugees' migration journeys to NZ. Participants encountered challenges in providing care to refugees with respect to time-limited consultations, variable use of interpreter services, fragmentation of care and lack of appropriate health infrastructure to ensure a fluid interface between PHC, secondary care and community support services to foster care continuity and access. The current business model of NZ general practice was perceived to interfere with value-driven care and discouraged tailoring of care to specific groups of patients, raising concerns about the 'fit' of mainstream general practice to address the complex healthcare needs of refugees. Addressing the needs of refugees across the social determinants of health involved a lot of 'behind the scenes work' particularly in the absence of shared information systems and the lack of well-established referral pathways to connect refugees to services beyond the health sector. This led to providers feeling overwhelmed and uncertain about their ability to provide appropriate care to refugees.

\section{Strengths and weaknesses of the study}

This qualitative interview study used purposive sampling to recruit a sample that was diverse in terms of the characteristics of the interviewed GPs and PNs. Through the choice of our qualitative exploratory design we were able to obtain detailed reflections from PHC professionals on the relational and structural dynamics enabling and restricting service delivery to refugees, highlighting implications at NZ health system, policy and practice levels. All participants were actively involved in providing care to refugees which contributed to the richness of the data, and some critically reflected on their own experiences of migration to NZ. It was appropriate that this study was based in a single health region, which provided rich context-specific findings to the benefit of the local health system.

We are cognisant of the timing of our research in the context of a programme that is still quite recent and that was subjected to ongoing adjustments during the course of the study. In particular, some general practices had recently disengaged from voluntary uptake of refugee families due to previous challenging experiences of providing care to the first few cohorts of refugees and the significant amount of supplementary work required. We also acknowledge that our participants comprised providers who may have been more favourable to the programme as others who did not participate and therefore views may not fully reflect the wider range of experiences of providing care to refugees. The findings also only reflect healthcare professionals' views, and we therefore need to seek the perspectives of refugees in future work to bring those viewpoints into dialogue to inform service improvement.

\section{Comparison with existing literature}

This is the first in-depth qualitative study seeking the perspectives of GPs and PNs caring for recently arrived refugees through mainstream NZ general practice. Our findings mirror themes interpreted in other studies internationally. They particularly highlight the importance of relationship-centred care to foster culturally appropriate PHC practice. This is captured in other research referring to the healthcare encounter as foundation for developing a rich cultural understanding of refugees' complex journeys and building trustful relationships. ${ }^{35} 36$ The study findings also support previous research which describe pillars of cross-cultural interactions, including taking active interest in refugees' background, language and culture and adopting a compassionate and empathetic approach. ${ }^{15} 1637$ Nevertheless, cross-cultural interactions 
are not without challenges and other research also reported on PHC teams presenting difficulties with supporting patients presenting with very high and sometimes unrealistic expectations of healthcare services often due to a lack of understanding of the health system in their new host country. ${ }^{26} 363839$

The study findings align with those outlined by other studies discussing challenges of working within the healthcare system when providing care to refugees. Mainstream PHC providers often lack professional support, particularly around abilities to address refugees' complex physical, psychological and social problems, as previously identified. ${ }^{3840}$ A recent Scottish qualitative study ${ }^{41}$ highlights the need to further strengthen GPs' competency in addressing social determinants of health to support their work with disadvantaged groups and maximise impact of PHC in tacking health disparities. ${ }^{42-44}$ This is also described in the nursing literature. ${ }^{45-47} \mathrm{PHC}$ is strategically positioned to play a key role in addressing social determinants of health but further efforts are needed to allow PHC professionals to practice at full scope in this particular domain. ${ }^{15} 4143454648$ Previous research has specifically identified a lack of educational support, debriefing opportunities and resources to build capacity for PHC professionals caring for refugees. ${ }^{14} 16$ This is often associated with PHC providers not always feeling prepared and supported to meet refugees' needs. ${ }^{141638}$ Findings from this study support those of Kai et $a t^{49}$ who identified the considerable uncertainty that health professionals may experience working with patients of differing ethnicity from their own, with a potential risk of professional disempowerment. Difficulties of ensuring efficient connections between PHC and other services for refugees are also reported in the literature, ${ }^{13}{ }^{50-53}$ and our findings further expand on this with rich narratives from participants about the potential professional distress associated with feeling disconnected and isolated in their professional role with refugees. Our findings also echo those of previous research that suggest that PHC professionals' difficulties in referring refugees to appropriate care can be accentuated when they found it difficult to navigate complex health systems themselves. ${ }^{36}{ }^{38}$ Participants from this study also identified resourcing and capacity as important barriers to effective PHC for refugees, and this has also been found in previous research. ${ }^{12} 146$ The study findings shed light on a lack of appropriate health infrastructure and a lack of readiness of local health systems to provide responsive PHC to refugees. Critical reflections need to be had around the availability of critical health infrastructure to support healthy resettlement, and particularly the availability of appropriate PHC services with strong support networks in place to ensure that PHC professionals feel empowered to address the needs of refugees. ${ }^{54}$

\section{Implications for health policy and practice}

This study particularly challenges the mainstream general practice model for providing PHC to refugees. GPs and PNs in this study were under-resourced, at both practice level and structural level, to provide effective care for refugees. The mainstream general practice model has been previously brought into question with concerns expressed about general practice not being fit for purpose for providing front-line refugee healthcare. ${ }^{55}$ This study contributes to a deeper exploration of the reasons for reluctance about the mainstream approach to refugee care with particular concerns raised about the perceived lack of flexibility of delivery mechanisms to ensure service responsiveness to the needs of refugees and the contradictory nature of the business ownership model of NZ general practice that was seen as competing with providers' moral commitment and responsibility to help. This aligns with recent discussions on the private ownership model of NZ general practice and its mixed fee for service/capitation funding model which contributes to access barriers to general practice services for vulnerable groups, including Māori, Pacific and those living in socioeconomically deprived areas. ${ }^{56}{ }^{57}$ A systematic scoping

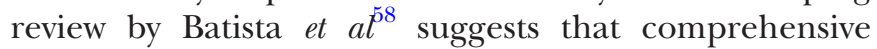
models of PHC underpinned by teamwork and interdisciplinary collaboration and strong links with communitybased services may be better equipped to address health needs across the social determinants of health and thus have more potential capabilities to reduce disparities for culturally diverse groups including refugees. ${ }^{58}$ The integration of specialised components with existing general practice models may also allow for multidisciplinary expertise to be more readily available to PHC teams who need enhanced support to provide high-quality care to refugees. Previous research indicated that it can be challenging to encourage general practices to accept refugees because they do not feel equipped to deal with the often unique challenges that refugees may bring. ${ }^{58}$ Ensuring that general practices stay committed to welcoming refugees is critical but this requires investment of sufficient resources to allow PHC professionals to feel supported in providing high-quality services.

Health professionals should be sufficiently resourced to meet the complex needs of refugees-not only to address complex medical and psychological conditions but also complex social conditions relating to refugees' migration trajectories and resettlement experiences. Promoting continuity in relationships with $\mathrm{PHC}$ providers is also important to foster relationship-centred care and build trust with refugee patients. It is critical to develop appropriate infrastructure to enable networking between health, social and community services to foster care continuity and avoid professional isolation and disconnect between the different providers involved in delivering refugee healthcare. Ensuring complementary models are in place to provide timely access to interpreters is imperative in order to avoid communication difficulties in the consultation (eg, a combination of in-person and telephone interpreters). This flexible approach may also increase uptake of interpreting services by clinicians. ${ }^{59}$ There is also a pressing need for best practice guidelines to ensure clear guidance to refugee care for PHC professionals. ${ }^{60}{ }^{61}$ Future research should consider exploring 
other healthcare professionals' experiences of caring for refugees including key stakeholders of refugee service delivery across sectors. Models of care for refugees also need to be investigated within the NZ context. Refugees' experiences of PHC services should also be documented to provide solid empirical foundation to inform service improvement and change of local health systems.

\section{CONCLUSIONS}

Culturally competent health systems enabling the delivery of high quality and accessible PHC services to culturally diverse communities is fundamental to health equity. For this to occur, refugee health needs to be at the forefront of the political agenda with robust evidence informing health system design and models of care for refugees. It is imperative that health systems and models of care enable PHC providers to feel supported and empowered to provide the best care possible to refugees.

\section{Twitter Lauralie Richard @LauralieRichard and Tim Stokes @StokesTim63}

Acknowledgements We would like to acknowledge the general practitioners and practice nurses who participated in this study.

Contributors LR conceived and designed the study with input from TS and CJ. GR conducted the interviews and qualitative data analysis was jointly undertaken by LR and GR, with input from TS and CJ. LR led the writing of the manuscript, with input from TS, CJ and GR. All authors reviewed and critiqued the manuscript and approved the final published version.

Funding This study was supported by a Dean's Bequest Research grant, Dunedin School of Medicine, University of Otago.

Competing interests None declared.

Patient consent for publication Not required.

Ethics approval Ethical approval was obtained from the University of Otago Human Ethics Committee (D18/052). Written informed consent was obtained from all participants.

Provenance and peer review Not commissioned; externally peer reviewed.

Data availability statement Full de-identified interview transcripts will not be shared. Informed consent, in line with the approving ethics committee, only allows for the use of de-identified extracts within research reporting and writing, in order to maintain the privacy of participants based in a defined regional area and population, thus making their identification with full transcripts more likely.

Open access This is an open access article distributed in accordance with the Creative Commons Attribution Non Commercial (CC BY-NC 4.0) license, which permits others to distribute, remix, adapt, build upon this work non-commercially, and license their derivative works on different terms, provided the original work is properly cited, appropriate credit is given, any changes made indicated, and the use is non-commercial. See: http://creativecommons.org/licenses/by-nc/4.0/.

ORCID iDs

Lauralie Richard http://orcid.org/0000-0002-2497-3857

Tim Stokes http://orcid.org/0000-0002-1127-1952

\section{REFERENCES}

1 Smith J, Daynes L. Borders and migration: an issue of global health importance. Lancet Glob Health 2016;4:e85-6.

2 Kirmayer LJ, Narasiah L, Munoz M, et al. Common mental health problems in immigrants and refugees: general approach in primary care. Can Med Assoc J 2011;183:E959-67.

3 Mangrio E, Sjögren Forss K. Refugees' experiences of healthcare in the host country: a scoping review. BMC Health Serv Res 2017; 17:814.

4 Hadgkiss EJ, Renzaho AMN. The physical health status, service utilisation and barriers to accessing care for asylum seekers residing in the community: a systematic review of the literature. Australian Health Review 2014;38:142-59.

5 Williams ME, Thompson SC. The use of community-based interventions in reducing morbidity from the psychological impact of conflict-related trauma among refugee populations: a systematic review of the literature. J Immigr Minor Health 2011;13:780-94.

6 Cheng I-H, Drillich A, Schattner P. Refugee experiences of general practice in countries of resettlement: a literature review. $\mathrm{Br} J$ Gen Pract 2015;65:e171-6.

7 Bhatia R, Wallace P. Experiences of refugees and asylum seekers in general practice: a qualitative study. BMC Fam Pract 2007;8.

8 Hacker K, Anies ME, Folb B, et al. Barriers to health care for undocumented immigrants: a literature review. Risk Manag Healthc Policy 2015;8:175-83.

9 Manchikanti P, Cheng I-H, Advocat J, et al. Acceptability of general practice services for Afghan refugees in south-eastern Melbourne. Aust J Prim Health 2017;23:87-91.

10 Cheng I-H, Vasi S, Wahidi S, et al. Rites of passage: improving refugee access to general practice services. Aust Fam Physician 2015;44:503-7.

11 Matlin SA, Depoux A, Schütte S, et al. Migrants' and refugees' health: towards an agenda of solutions. Public Health Rev 2018;39:27.

12 Suphanchaimat R, Kantamaturapoj K, Putthasri W, et al. Challenges in the provision of healthcare services for migrants: a systematic review through providers' lens. BMC Health Serv Res 2015;15.

13 Joshi C, Russell G, Cheng I-H, et al. A narrative synthesis of the impact of primary health care delivery models for refugees in resettlement countries on access, quality and coordination. Int $J$ Equity Health 2013;12:88.

14 Lindenmeyer A, Redwood S, Griffith L, et al. Experiences of primary care professionals providing healthcare to recently arrived migrants: a qualitative study: Table 1. BMJ Open 2016;6:e012561.

15 Ogunsiji $\mathrm{O}, \mathrm{Ng}$ Chok $\mathrm{H}$, Mashingaidze G, et al. "I am still passionate despite the challenges": Nurses navigating the care for refugees. $J$ Clin Nurs 2017:1-10.

16 Robertshaw L, Dhesi S, Jones LL. Challenges and facilitators for health professionals providing primary healthcare for refugees and asylum seekers in high-income countries: a systematic review and thematic synthesis of qualitative research. BMJ Open 2017;7:e015 981-e81.

17 Hobbs M, Moor C, Wansborough T, et al. The health status of asymlum seekers screened by Auckland public health in 1999 and 2000. N Z Med J 2002;115:1-7.

18 Blakely $T$. Health needs of Cambodian and Vietnamese refugees in Porirua. N Z Med J 1996;109:381-4.

19 Pernice R, Brook J. Refugees' and immigrants' mental health: association of demographic and Post-Immigration factors. J Soc Psychol 1996;136:511-9.

20 Maydell-Stevens E, Masgoret AM, Ward T. Problems of psychological and sociocultural adaptation among RussianSpeaking immigrants in New Zealand. Soc Policy J New Zealand 2007;30:178-98.

21 Kanengoni B, Andajani-Sutjahjo S, Holroyd E. Setting the stage: reviewing current knowledge on the health of new Zealand immigrants - an integrative review. PeerJ 2018;6:e5184.

22 Rungan S, Reeve AM, Reed PW, et al. Health needs of refugee children younger than 5 years arriving in New Zealand. Pediatr Infect Dis J 2013;32:e432-6.

23 Birukila G, Brunton C, Dickson N. Hiv-Related risk factors among black African migrants and refugees in Christchurch, New Zealand: results from the Mayisha-NZ survey. N Z Med J 2013;126:19-27.

24 Gray B, Stanley J, Stubbe M, et al. Communication difficulties with limited English proficiency patients: clinician perceptions of clinical risk and patterns of use of interpreters. N Z Med J 2011;124:23.

25 Babar Z-U-D, Pengelly K, Scahill SL, et al. Migrant health in New Zealand: exploring issues concerning medicines access and use. $J$ Pharmaceut Health Servic Res 2013;4:41-9.

26 Lawrence J, Kearns R. Exploring the 'fit' between people and providers: refugee health needs and health care services in $\mathrm{Mt}$ Roskill, Auckland, New Zealand. Health Soc Care Community 2005;13:451-61.

27 Shrestha-Ranjit J, Patterson E, Manias E, et al. Effectiveness of primary health care services in addressing mental health needs of minority refugee population in New Zealand. Issues Ment Health Nurs 2017;38:290-300.

28 New Zealand Immigration. Supporting refugees and asylum seekers. Available: https://www.immigration.govt.nz/about-us/what-we-do/ our-strategies-and-projects/supporting-refugees-and-asylumseekers [Accessed 23 Nov 2019]. 
29 New Zealand Immigration. Immigration Factsheets. Refugees and asylum seekers. In: Ministry of business innovation and employment. New Zealand Government, ed, 2018.

30 Gauld R. The New Zealand Health Care System. In: Mossialos E, Wenzl M, Osborn R, et al, eds. 2015 international profiles of health care systems. New York: Commonwealth Fund, 2016.

31 Statistics New Zealand. 2013 census QuickStats about Dunedin City, 2013: 23.

32 Crabtree B, Miller W. Doing qualitative research. London: Sage Publications, 1999.

33 Miles MB, Huberman AM, Saldana J. Qualitative data analysis. A methods sourcebook. Arizona, USA: Sage Publications, 2019.

34 Tong A, Sainsbury P, Craig J. Consolidated criteria for reporting qualitative research (COREQ): a 32-item checklist for interviews and focus groups. Int J Qual Health Care 2007;19:349-57.

35 Isaacs S, Valaitis R, Newbold KB, et al. Competence trust among providers as fundamental to a culturally competent primary healthcare system for immigrant families. Prim Health Care Res Dev 2013;14:80-9.

36 Farley R, Askew D, Kay M. Caring for refugees in general practice: perspectives from the coalface. Aust J Prim Health 2014;20:85-91.

37 Suurmond J, Seeleman C, Rupp I, et al. Cultural competence among nurse practitioners working with asylum seekers. Nurse Educ Today 2010;30:821-6.

38 Jensen NK, Norredam M, Priebe S, et al. How do general practitioners experience providing care to refugees with mental health problems? A qualitative study from Denmark. BMC Fam Pract 2013;14:17.

39 Suurmond J, Rupp I, Seeleman C, et al. The first contacts between healthcare providers and newly-arrived asylum seekers: a qualitative study about which issues need to be addressed. Public Health 2013;127:668-73.

40 Fair GL, Harris MF, Smith MM. Transition from an asylum seekerspecific health service to mainstream primary care for communitybased asylum seekers: a qualitative interview study. Public Health Res Pract 2018;28:2811805.

41 Babbel B, Mackenzie M, Hastings A, et al. How do general practitioners understand health inequalities and do their professional roles offer scope for mitigation? constructions derived from the deep end of primary care. Crit Public Health 2019;29:168-80.

42 Rasanathan K, Montesinos EV, Matheson D, et al. Primary health care and the social determinants of health: essential and complementary approaches for reducing inequities in health. $J$ Epidemiol Community Health 2011;65:656-60.

43 Taylor J, Lamaro Haintz G, Haintz GL. Influence of the social determinants of health on access to healthcare services among refugees in Australia. Aust J Prim Health 2018;24:14-28.

44 Jones D, Gill PS. Refugees and primary care: tackling the inequalities. BMJ 1998;317:1444-6.

45 Reutter L, Kushner KE. 'Health equity through action on the social determinants of health': taking up the challenge in nursing. Nurs Inq 2010;17:269-80.
46 Cohen BE, Reutter L. Development of the role of public health nurses in addressing child and family poverty: a framework for action. $J$ Adv Nurs 2007;60:96-107.

47 Smith GR. Health disparities: what can nursing do? Policy Polit Nurs Pract 2007;8:285-91.

48 Halcomb E, Stephens M, Bryce J, et al. The development of professional practice standards for Australian general practice nurses. J Adv Nurs 2017;73:1958-69.

49 Kai J, Beavan J, Faull C, et al. Professional uncertainty and Disempowerment responding to ethnic diversity in health care: a qualitative study. PLoS Med 2017;4:e323.

50 McBride J, Block A, Russo A. An integrated healthcare service for asylum seekers and refugees in the south-eastern region of Melbourne: Monash health refugee health and wellbeing. Aust $J$ Prim Health 2017:23:323-8.

51 McMurray J, Breward K, Breward M, et al. Integrated primary care improves access to healthcare for newly arrived refugees in Canada. $J$ Immigr Minor Health 2014;16:576-85.

52 Phillips C, Sally H, Nicholas E, et al. People-centred integration in a refugee primary care service: a complex adaptive system perspective. Journal of Integrated Care 2017;25:26-38.

53 White CC, Solid CA, Hodges JS, et al. Does integrated care affect healthcare utilization in Multi-problem refugees? J Immigr Minor Health 2015;17:1444-50.

54 Sypek S, Clugston G, Phillips C. Critical health infrastructure for refugee resettlement in rural Australia: case study of four rural towns. Aust J Rural Health 2008;16:349-54.

55 Johnson DR, Ziersch AM, Burgess T. I don't think general practice should be the front line: Experiences of general practitioners working with refugees in South Australia. Aust New Zealand Health Policy 2008;5:20.

56 Gauld R, Atmore C, Baxter J, et al. The 'elephants in the room' for New Zealand's health system in its 80th anniversary year: general practice charges and ownership models. New Zealand Med $\mathrm{J}$ 2019;132:8-14.

57 Sreedhar S, Richard L, Stokes T. Multimorbidity and multiple social disadvantage in a new Zealand high-needs free primary healthcare clinic population: a crosssectional study. New Zealand Med J 2019;132:42-51.

58 Batista R, Pottie K, Bouchard L, et al. Primary health care models addressing health equity for immigrants: a systematic scoping review. J Immigrant Minority Health 2018;20:214-30.

59 Phillips CB, Travaglia J. Low levels of uptake of free interpreters by Australian doctors in private practice: secondary analysis of national data. Australian Health Review 2011;35:475-9.

60 Pottie K, Batista R, Mayhew M, et al. Improving delivery of primary care for vulnerable migrants: Delphi consensus to prioritize innovative practice strategies. Can Fam Physician 2014;60:e32-40.

61 Griswold KS, Pottie K, Kim I, et al. Strengthening effective preventive services for refugee populations: toward communities of solution. Public Health Rev 2018;39. 